\title{
Mode of delivery and outcome of breech presentation: a prospective observational study in a tertiary centre
}

\author{
Rashmi Kumar Karning, Bhanu B. T.*, Sarojini
}

Department of Obstetrics and Gynecology, Bangalore Medical College and Research Centre, Bangalore, Karnataka, India

Received: 18 May 2017

Accepted: 17 June 2017

*Correspondence:

Dr. Bhanu B. T.,

E-mail: docbhanubt@gmail.com

Copyright: (c) the author(s), publisher and licensee Medip Academy. This is an open-access article distributed under the terms of the Creative Commons Attribution Non-Commercial License, which permits unrestricted non-commercial use, distribution, and reproduction in any medium, provided the original work is properly cited.

\begin{abstract}
Background: Breech presentation is the commonest malpresentation with the incidence of 3-4\% at term. This study was done with the objective of studying the mode of delivery in breech presentation and to compare the maternal and fetal outcome in patients delivered vaginally to those delivered by cesarean section.

Methods: This prospective observational study was conducted in Vanivilas Hospital, affiliated to Bangalore Medical College and Research Institute, from June 2014 to May 2015. The study group included 509 patients with breech presentation who were studied with respect to their gestational age, birth weight, type of breech, mode of delivery, maternal and perinatal outcome.

Results: The incidence of breech presentation was $2.92 \%$ (509) among 17454 total deliveries with the incidence of $3.17 \%$ in primi and $2.73 \%$ in multies. $193(38 \%)$ patients had vaginal breech delivery and $316(62 \%)$ delivered by LSCS. Apgar score of less than 7 at 1 minute was seen with $21.42 \%$ of vaginally delivered fetuses and $9.09 \%$ of fetuses delivered by cesarean section. The perinatal mortality was $1.6 \%$ (8 cases) in vaginal group $0.8 \%$ ( 4 cases) in LSCS group. The short term maternal complications in LSCS group was $7.62 \%$ and in vaginal delivery group was $3.09 \%$.

Conclusions: The short term maternal morbidity is higher in patients with cesarean section compared to those with vaginal breech delivery. Perinatal outcome is better in babies delivered by cesarean section. Still vaginal breech delivery can be an option for breech babies with proper selection and when conducted by a skilled obstetrician.
\end{abstract}

Keywords: Breech presentation, Mode of delivery, Vaginal breech delivery

\section{INTRODUCTION}

Breech presentation is a longitudinal fetal lie in which the fetal podalic pole consisting of the buttocks, feet or the knees is the leading pole. The incidence of breech presentation decreases with increasing gestational age. While $20-25 \%$ of fetuses under 28 weeks are breech, only $7-16 \%$ are breech at 32 weeks, with the incidence of breech being 3-4\% at term. ${ }^{1}$ Depending upon the varying amount of extension, different types of breech are classified as
1. Complete/Flexed breech

2. Incomplete breech

- Frank/Extended breech

- Footling breech

- Kneeling breech

Clinically breech can be classified as uncomplicated breech and complicated breech when breech is associated with prematurity, placenta previa, contracted pelvis, twins etc. Causes of breech presentation are- prematurity, 
altered intrauterine contour or volume like uterine anomalies, uterine leiomyomata, placental abnormalities, multiparity, extremes of amniotic fluid volume, fetal anomalies, multiple gestation.

Ultrasonographic examination in breech presentation helps us to know the type of breech, attitude of fetal head, nuchal arms and estimated fetal weight.

Different modes of delivery for breech presentation can be spontaneous breech delivery, assisted breech delivery, breech extraction and cesarean section. It is essential for clinicians to maintain the skills of vaginal breech delivery especially in a country like ours with limited access to operative delivery and in situations such as precipitous labour, second stage labour referrals, delivery of an anomalous or a dead fetus or mother's preference for vaginal birth. The vast majority of the morbidity and mortality associated with breech delivery is attributed to three factors-cord compression, occurrence of nuchal arms and difficulty in birth of the aftercoming head. Cesarean section for breech also requires skill and expertise as the problems of birth injury, traction on the fetal spine and difficulties of the after coming head still remain. Delivery of breech fetus at cesarean mirrors an assisted vaginal breech delivery.

To compare the outcome of planned vaginal delivery versus planned cesarean delivery in selected breech presentation pregnancies the Term Breech Trial was conducted. This trial interpreted that planned cesarean section is better than planned vaginal birth for the term fetus in breech presentation and serious maternal complications are similar between the two groups. ${ }^{2}$

With a policy of planned cesarean sections, for every additional 14 cesarean sections done, one baby will avoid death or a serious morbidity. However, the investigators of the trial, themselves reported in a follow up study that planned cesarean section was not associated with a reduction in the risk of death or neurodevelopmental delay in children at the age of two years. ${ }^{3}$ This study was conducted in a tertiary referral center, to study the mode of delivery in breech presentation and to compare the maternal and fetal outcome in patients delivered vaginally to those delivered by cesarean section.

\section{METHODS}

This clinical study was conducted in Vanivilas Hospital, affiliated to Bangalore Medical College and Research Institute from June 2014 to May 2015.

This is a prospective observational study. The study group included 509 patients with breech presentation among the 17454 patients who delivered in this hospital during the study period. Patients with singleton pregnancy with breech presentation with more than 28 weeks of gestation were included in the study.
Patients with multifetal gestation, compound presentation and those delivered by breech before 28weeks of pregnancy were excluded from the study.

These patients were studied with respect to their gestational age, birth weight, type of breech, mode of delivery, maternal and perinatal outcome.

Detailed history was taken and examination was done for all the patients with emphasis on any associated complicating factors. This was followed by routine blood investigations and an ultrasound scan whenever feasible. Vaginal delivery was allowed in cases where there was reassuring CTG at admission, estimated fetal weight was not more than $3.5 \mathrm{kgs}$, with no fetopelvic disproportion, no placenta praevia, frank or complete breech and in case of anomalous baby. The patients who were selected for vaginal delivery were carefully monitored and assisted breech delivery was conducted in the presence of a paediatrician with the resuscitation kit.

Cesarean section was carried out as an elective procedure or on an emergency basis in cases of fetopelvic disproportion, placenta praevia, fetal distress, previous cesarean section, footling breech, cord prolapse or cord presentation, failure to progress, oligohydramnios etc.

\section{RESULTS}

There were 17454 deliveries in Bangalore Medical College and research institute during the study period between June 2014 and May 2015. Out of these, 509 were breech deliveries. The incidence of breech presentation was $2.92 \%$.

Maximum incidence was seen in the age group between 26-30 years and least incidence was in the age group below $<20$ years.

Table 1: Parity and number of cases.

\begin{tabular}{|lll|}
\hline Parity & No. of cases & $\%$ \\
\hline Primi & 236 & 46.27 \\
\hline Gravida 2 & 146 & 28.65 \\
\hline Gravida 3 & 88 & 17.25 \\
\hline Gravida 4 & 32 & 6.27 \\
\hline Gravida 5 & 8 & 1.56 \\
\hline
\end{tabular}

Table 1 shows the distribution of breech presentation and the parity.

The incidence of breech presentation in primi was $3.17 \%$ and in multigravida it was $2.73 \%$. Frank breech was the commonest type of breech presentation. Table 2 shows the types of breech presentation.

In primigravida, frank breech was more frequently seen accounting for $82.2 \%$ where as in multigravida, complete breech was more common being $55.47 \%$. Footling is the least common in both but more seen in multigravida. 
Table 2: Type of breech.

\begin{tabular}{|lll|}
\hline Type of breech & No. of cases & $\%$ \\
\hline Complete & 184 & 36.07 \\
\hline Frank & 278 & 54.52 \\
\hline Footling & 46 & 9.11 \\
\hline Kneeling & 2 & 0.3 \\
\hline
\end{tabular}

The incidence of breech presentation was higher before 37 weeks gestation which was $62.74 \%$ compared to after 37 weeks which was $37.26 \%$.

Table 3: Complications and number of cases.

\begin{tabular}{|l|l|}
\hline Complications & No. of cases \\
\hline PIH & 60 \\
\hline Eclampsia & 18 \\
\hline Abruption & 14 \\
\hline IUGR & 40 \\
\hline Previous LSCS & 60 \\
\hline Previous 2 LSCS & 6 \\
\hline Oligohydramnios & 46 \\
\hline Polyhydramnios & 8 \\
\hline Placenta praevia & 15 \\
\hline Anemia & 20 \\
\hline PPROM & 28 \\
\hline Chronic HTN & 5 \\
\hline Seizure disorder & 3 \\
\hline Thyroid disorder & 4 \\
\hline GDM & 15 \\
\hline Bronchial asthma & 4 \\
\hline Previous myomectomy & 2 \\
\hline Heart disease & 5 \\
\hline
\end{tabular}

About $48 \%$ of the cases were complicated by factors other than prematurity. In some cases, there were more than one complicating factors (Table 3 ).

Table 4: Uterine abnormality.

\begin{tabular}{|ll|}
\hline Uterine abnormality & No. of cases \\
\hline Biocornuate & 4 \\
\hline Unicornuate & 18 \\
\hline Septate & 8 \\
\hline Subseptate & 8 \\
\hline Fibroid & 12 \\
\hline
\end{tabular}

50 cases had uterine abnormality giving an incidence of $9.8 \%$ (Table 4).

15 fetuses had congenital abnormality which included hydrocephalous, Dandy Walker malformation, spina bifida, achandrogenesis, osteogenesis imperfecta, renal agenesis and congenital dislocation of the hip.

The rate of congenital anomaly of fetus in this study was $3.13 \%$. $193(38 \%)$ patients had vaginal breech delivery and $316(62 \%)$ delivered by LSCS.
LSCS was the most frequent mode of delivery in both primigravida and multigravida, but assisted breech deliveries were more common in multigravida. 24 $(10.16 \%)$ primigravidae and $86(31.5 \%)$ multigravidae had assisted breech deliveries.

Table 5: Indications for LSCS.

\begin{tabular}{|ll|}
\hline Indication & No. of cases \\
\hline Patient's request & 120 \\
\hline Fetopelvic disproportion & 102 \\
\hline Cord prolapse / presentation & 12 \\
\hline Oligohydramnios & 28 \\
\hline Previous LSCS & 56 \\
\hline Footling presentation & 23 \\
\hline Supracervical fibroid & 2 \\
\hline Placenta praevia & 15 \\
\hline Previous 2 LSCS & 5 \\
\hline Acute fetal distress & 20 \\
\hline Eclampsia & 12 \\
\hline Previous $4^{\text {th }}$ degree perineal tear & 2 \\
\hline PPROM & 20 \\
\hline
\end{tabular}

The most common indications for LSCS were fetopelvic disproportion and patient's request. There was overlap of indication between many cases. Table 5 shows the indications for LSCS. $21.42 \%$ of vaginally delivered fetuses had an Apgar score less than 7 at one minute whereas only $9.09 \%$ of fetuses delivered by cesarean section had such low Apgar scores.

There were 94 admissions to neonatal unit. $21.64 \%$ (42) of vaginally delivered fetuses and $16.5 \%$ (52) of fetuses delivered by cesarean section were admitted in neonatal unit. Two babies which were delivered vaginally had fracture of femur.

Table 6: Cause of perinatal death.

\begin{tabular}{|ll|}
\hline Causes of Perinatal Death & No. of fetuses \\
\hline Intrauterine fetal demise & 22 \\
\hline Prematurity & 3 \\
\hline Severe birth asphyxia & 4 \\
\hline Bilateral Renal Agenesis & 1 \\
\hline Dandy Walker Malformation & 1 \\
\hline Sepsis & 3 \\
\hline
\end{tabular}

There were 34 perinatal deaths out of which 22 patients had intrauterine fetal demise at admission. The perinatal mortality rate in this study is $6.66 \%$. Table 6 shows the causes of perinatal death. More perinatal deaths were seen in the fetuses less than 37 weeks gestations amounting to $82 \%$ of perinatal mortality.

Excluding the cases of IUFD at admission, the perinatal mortality was more among vaginally delivered patients which was $1.6 \%$ ( 8 cases) and it was $0.8 \%$ (4 cases) in patients delivered by LSCS. The number of complications in patients delivered by cesarean section 
were more $(7.59 \%)$ than vaginally delivered patients $(3.1 \%)$. The overall maternal complication rate was $5.8 \%$ (Table 7).

Table 7: Maternal complications.

\begin{tabular}{|lll|}
\hline \multirow{2}{*}{$\begin{array}{l}\text { Vaginal } \\
\text { delivery }\end{array}$} & Complications & No. of cases \\
& Atonic PPH & 3 \\
\cline { 2 - 3 } & Haematoma & 2 \\
\hline \multirow{3}{*}{$\begin{array}{l}\text { Cesarean } \\
\text { delivery }\end{array}$} & Febrile morbidity & 1 \\
& Wound gape & 4 \\
\hline & Inverted T incision & 4 \\
\hline
\end{tabular}

\section{DISCUSSION}

The maternal complications and fetal morbidity and mortality are higher in case of breech presentation compared to vertex presenting fetuses. The maternal and fetal outcomes of breech presenting fetuses in this observational study has been compared with other studies. The incidence of breech delivery was $2.92 \%$ comparable to the incidences found by Gilbert et al and Moodley et al which were $3 \%$ and $2.4 \%$ respectively. ${ }^{4,5}$ In the present study, the maximum incidence of breech was seen in the age group between $26-30$ years which was $37.64 \%$ which correlated with the study by Han et al in Singapore showing an incidence of $36.2 \%$ in the same age group. ${ }^{6}$

The incidence of complete breech in our study was $36.07 \%$, extended breech was $54.52 \%$, and footling breech was $9.11 \%$ which was comparable with the Term Breech Trial. ${ }^{2}$ In the present study, assisted vaginal breech delivery was the mode of delivery in $38 \%$ of cases and LSCS was done in $62 \%$. The studies by Alarab et al, Moodley et al and Han et al have lower vaginal delivery rates compared to our study. ${ }^{5-7}$ Our hospital being a tertiary referral center, there are many breech presentation cases brought in active labour, who cannot be immediately taken for cesarean. $10.16 \%$ of primigravidae delivered vaginally whereas as $89.84 \%$ underwent cesarean section. The vaginal delivery rate in multigravidae was 3 times greater i.e. $31.5 \%$ and cesarean section rate was $68.62 \%$.

The results of present study are comparable to the study by Alarab et al with a vaginal delivery rate of $15.50 \%$ and a cesarean section rate of $84.50 \%$ in primigravidae and a rate of vaginal delivery of $32.95 \%$ and cesarean rate of $67.05 \%$ in multigravidae. ${ }^{7}$

In present study, the Apgar score less than 7, was found more in vaginally delivered patients $(21.4 \%)$. The same results were found in The Term Breech Trial, Alarab et al and Pradhan et al where Apgar score less than 7 were found more in vaginally delivered fetuses., , $^{2,8}$ The perinatal mortality rate in this study was $6.66 \%$. Excluding the cases of intrauterine fetal demise perinatal mortality rate is $2.46 \%$. The Term Breech Trial had the perinatal mortality rate of $0.3 \%$ in countries with low perinatal mortality and $1.2 \%$ in countries with high perinatal mortality rate. ${ }^{2}$ The perinatal mortality rate in the vaginally delivered group was $1.3 \%$ when compared to $0.3 \%$ in the planned cesarean group which was $1.6 \%$ and $0.82 \%$ respectively in our study. Hence the perinatal mortality was more in vaginal delivery group in comparison with cesarean group. The study by Gilbert et al and the study by Rietberg et al also showed similar results. ${ }^{4,9}$

Table 8: Maternal complication rate with respect to mode of delivery in various studies.

\begin{tabular}{|llll|}
\hline Studies & $\begin{array}{l}\text { Overall } \\
\text { Rate }\end{array}$ & $\begin{array}{l}\text { Maternal complication rate } \\
\text { Vaginal } \\
\text { delivery }\end{array}$ & $\begin{array}{l}\text { Cesarean } \\
\text { section }\end{array}$ \\
\hline Rauf et al & $6 \%$ & $12.5 \%$ & $87.5 \%$ \\
\hline $\begin{array}{l}\text { Moodley } \\
\text { et al }\end{array}$ & $4.72 \%$ & $9.1 \%$ & $90.9 \%$ \\
\hline $\begin{array}{l}\text { Term } \\
\text { breech trial }\end{array}$ & $3.5 \%$ & $49 \%$ & $51 \%$ \\
\hline $\begin{array}{l}\text { Present } \\
\text { study }\end{array}$ & $5.8 \%$ & $22.5 \%$ & $77.5 \%$ \\
\hline
\end{tabular}

The maternal complication rate in our study was $5.8 \%$ which correlated with the study by Rauf et al, with a complication rate of $6 \%$ and by Moodley et al, with the rate of $4.72 \% .{ }^{5,10}$

In the Term Breech Trial, there was not much difference in the maternal morbidity between the two groups of planned vaginal delivery versus planned cesarean section $(3.2 \% \mathrm{v} / \mathrm{s} 3.9 \%){ }^{2}$ This observation tilted the guidelines in favour of elective cesarean section as the mode of delivery. Later studies by Moodley et al, Han et al and Rauf et al concluded that the maternal complications were more in cesarean delivery when compared to vaginal delivery which correlates well with the present study (Table 8). 5,6,10

\section{CONCLUSION}

Based on present study, it can be concluded that the maternal short-term morbidity was higher in patients who delivered by cesarean section compared to those who delivered vaginally. Fetal morbidity was lesser and Apgar scores better in babies delivered by cesarean section. Perinatal mortality was higher in babies delivered vaginally. Hence, we can conclude that vaginal delivery is not a completely safe option but can be considered as a safe route for breech babies as long as the selection criteria is fulfilled and delivery is conducted by a skilled obstetrician with intrapartum fetal monitoring.

\section{Funding: No funding sources \\ Conflict of interest: None declared}

Ethical approval: The study was approved by the Institutional Ethics Committee 


\section{REFERENCES}

1. Hickok DE, Gordon DC, Milberg JA, Williams MA, Daling JR. The frequency of breech presentation by gestational age at birth: a largepopulation based study. Am J Obstet Gynecol. 1992;166:851-2.

2. Hannah ME, Hannah MJ, Hewson SA, Hodnett ED, Saigal S, Willan AR et al. Planned cesarean section versus planned vaginal birth for breech presentation at term: a randomised multicentre trial. Term Breech Trial Collaborative Group. Lancet. 2000;256:1375.

3. Whyte H, Hannah ME, Saigal S, Hannah WJ, Hewson S, Amankwah K et al. Outcome of children at 2years after planned cesarean birth versus planned vaginal birth for breech presentation at term. The International Randomised Term Breech Trial. Am J Obstet Gynecol. 2004;191(3):864-71.

4. Gilbert WM, Hicks SM, Boe NM, Danielsen B. Vaginal versus cesarean delivery for breech presentation in California: a population-based study. Obstet Gynecol. 2003;102(5):911-7.

5. Moodley J, Khedhen SM, Devjee J. Breech presentation at a district level hospital in South Africa. SA Fan Pract. 2010;52(1):64-68.

6. Han HC, Tan KH, Chew SY. Management of breech presentation at term. Singapore Med J. 1993;34:247252.
7. Alarab M, Regan C, O'Connell MD. Singleton vaginal breech delivery at term: Still a safe option. Obstet Gynecol. 2004;103:407.

8. Pradhan P, Mohajer M, Deshpande S. Outcome of term breech births: 10-year experience at a district general hospital. BJOG: Int $\mathrm{J}$ Obstet Gynecol. 2005;112(2):218-22.

9. Rietberg CC, Elferink-Stinkens PM, Brand R, Loon AJ, Hemel OJ, Visser GH. Term breech presentation in The Netherlands from 1995 to 1999: mortality and morbidity in relation to the mode of delivery of 33,824 infants. BJOG: Int J Obstet Gynecol. 2003;110(6):604-9.

10. Rauf B, Ayub T. Maternal and Perinatal outcome in term singleton breech presentation. J Postgraduate Med Institute. 2001;18(3):373-9.

Cite this article as: Karning RK, Bhanu BT, Sarojini. Mode of delivery and outcome of breech presentation: a prospective observational study in a tertiary centre. Int J Reprod Contracept Obstet Gynecol 2017;6:3409-13. 